\title{
Mobbing (Assédio Psicológico-Moral) no Ambiente de Trabalho: uma Visão Crítica Contemporânea
}

\author{
Mobbing (Psychological-Moral Harassment) in the Work Environment: a \\ Contemporary Critical View \\ Mobbing (Acoso Psicológico-Moral) en el Anbiente de Trabajo: una Visión Critica \\ Contenporánea
}

Liliana Adolpho Magalhães Guimarães ${ }^{1}$

Eveli Freire Vasconcelos ${ }^{1}$

Universidade Católica Dom Bosco

\begin{abstract}
Resumo
Este estudo apresenta uma visão crítica da produção do atual conhecimento do fenômeno mobbing (assédio psicológico ou moral) no trabalho, sob a ótica da saúde mental. Descreve o cenário sócio-econômico-políticoorganizacional contemporâneo para sua ocorrência e suas principais características. Aponta para a pertinência do termo assédio psicológico ou mobbing em detrimento do termo assédio moral, embora reconheça que o uso desse último esteja consagrado na literatura nacional e hispânica. Descreve pontos polêmicos sobre a caracterização do fenômeno. Apresenta as consequências do mobbing para a saúde, para a qualidade de vida e para a sociedade. Pontua aspectos preventivos. Conclui que a adequada abordagem do problema somente será possível por meio de seu reconhecimento e enfrentamento coletivo, direto e claro e de um entendimento e intervenção interdisciplinar, visto que se trata de um fenômeno multidimensional.

Palavras-chave: Mobbing, assédio psicológico, assédio moral, crítica, conceito, trabalho.
\end{abstract}

\begin{abstract}
This paper reports on a critical view of the production of current knowledge of the mobbing at workplace (psychological harassment) from the perspective of mental health, Describes the socio-economical-political and organizational contemporary scenario. Show their main characteristics, pointing to the relevance of the term mobbing (psychological harassment) at the workplace to the detriment of bullying and moral harassment, while recognizing that the use of the latter is enshrined in the national and Hispanic literature. Concludes that, the appropriate approach to the problem will only be possible through its recognition and collective coping, direct and clear and an interdisciplinary understanding and intervention, since it is a multidimensional phenomenon.

Keywords: Mobbing, psychological harassment, workplace, work.
\end{abstract}

\section{Resumen}

El presente estudio ofrece una visión critica de la producción actual del conocimiento sobre el fenómeno mobbing (acoso psicológico o moral) en el trabajo, bajo la óptica de la salud mental. Describe el escenario socio-económicopolítico-organizacional contemporáneo que lo caracteriza y lo permite acontecer. Señala hacia la pertinencia de la expresión acoso psicológico o mobbing en detrimento de la expresión acoso moral, aún reconociendo que el uso de este ultimo encuéntrase consagrado en la literatura nacional e hispánica. Describe aspectos polémicos en relación a la caracterización del fenómeno. Presenta las consecuencias del mobbing para la salud, para la calidad de vida y para la sociedad. Hace indicaciones respecto a aspectos preventivos. Concluye que el adecuado abordaje del problema solo será posible por medio de su reconocimiento e enfrentamiento colectivo, directo y claro y de una comprensión e intervención interdisciplinar, ya que se trata de un fenómeno multidimensional.

Palabras clave: Mobbing, acoso psicológico, acoso moral, critica, concepto, trabajo.

\section{Introdução}

\section{Trabalho e Mobbing: contemporaneidade}

$\mathrm{O}$ trabalho moderno tem exigido mais das pessoas do ponto de vista psicológico, do que do físico. Cada vez mais, observa-se e relata-se o sofrimento psicológico no ambiente de trabalho.

Com o processo da globalização, as organizações contemporâneas nas sociedades capitalistas têm enfrentado constantes pressões sobre mudanças (Frenkel \& Kim, 2004), com a criação de vantagens

\footnotetext{
1 Endereço: Curso de Psicologia UCDB

Av. Tamandaré, 6.000 - bloco B - Bairro: Jardim Seminário Cep: 79.119-900 - Telefones: (67) 3321.3456 e" 3312. 3464 E-mail: psic@ucdb.br
}

competitivas (Chew \& Horwitz, 2004), a necessidade de mudanças contínuas (Fay \& Lührmann, 2004) e com a pressão para o aumento do desempenho. (Worrall, Parkes \& Cooper, 2004).

Vive-se uma época em que os salários perdem, constantemente, seu poder aquisitivo e, ao contrário disso, exige-se mais produtividade e especialização por parte do trabalhador. Em muitos casos, a solução apontada como remédio para curar os males da precariedade e da extrema seletividade do trabalho é a educação - elemento "salvador" -, que deve ser constantemente atualizado. É a lógica neoliberal, que legitima uma vasta reestruturação produtiva.

O Estado retira e diminui benefícios e direitos já conquistados pelo trabalhador, em um processo de enxugamento que modifica a relação capital-trabalho. 
Este modelo de desenvolvimento econômico faz surgir novas relações profissionais, muitas vezes desfavoráveis ao empregado, como o contrato de trabalho por tempo determinado, além de variadas formas de terceirização e modernização, que conduzem ao subemprego e ao trabalho informal. As organizações nacionais, pressionadas pelo processo de globalização, substituem cada vez mais o homem pela máquina. Assim, novas tecnologias são implementadas nas empresas, obrigando o trabalhador a adaptar-se rapidamente a elas e lhe impondo um novo perfil de profissional tecnicista.

Para Rantanen (2000), em muitas partes do mundo a globalização trouxe consigo o crescimento da inequidade e a diminuição da prioridade da dimensão social. Em outras palavras, a globalização e a desregulação resultaram em aumento da distância entre ricos e pobres, além da exclusão e marginalização do operário, particularmente nos países em desenvolvimento.

A evidência de reação das empresas à incerteza produzida por todas essas pressões pode ser observada no crescimento das atuais abordagens de gestão, tais como o downsizing (McKinley, Zhao \& Rust, 2000), a melhoria da liderança gerencial (Parry \& Proctor-Thompson, 2003), a orientação para a empregabilidade (van Dam, 2004), entre outras. Juntos, esses termos indicam um discurso centrado na mudança organizacional, que está afetando as organizações e os trabalhadores e traz como um dos reflexos o assédio moral/psicológico no ambiente de trabalho, o mobbing ${ }^{1}$.

O fenômeno do mobbing é mundialmente reconhecido como um problema sério e complexo, advindo de fatores sociais, econômicos, organizacionais e culturais. Essa forma de violência psicológica no trabalho está descrita pela Organização Internacional do Trabalho (OIT) (Chappel \& Di Martino, 2001, p.4) e pela Organização Mundial da Saúde (OMS) (2004). Ambas reconhecem que o fenômeno constitui um problema internacional crescente a cada ano e que, em grande parte, ainda é ignorado e subestimado.

Recentes estudos, realizados em diferentes países, apontam para o fenômeno do assédio moralpsicológico como algo mundial, não específico, de uma dada cultura ou país (Shallcross, Sheehan,\& Ramsay, 2008; Ramsay, Barker, \& Shallcross, 2008; Flores, Almegua \& Mendoza (2007); Einarsen, Hoel, Zapf, \& Cooper, 2003). Tem sido constatada sua ocorrência mesmo em países que possuem uma legislação bem estabelecida para a proteção dos trabalhadores (Hirigoyen, 2002b).

Enquanto o problema do mobbing está legislado em muitos países europeus e escandinavos, (Chappell \& Di Martino, 2001), ainda não é formalmente reconhecido nos países de língua primariamente

1 Nesse artigo, os termos assédio moral, assédio psicológico e mobbing serão utilizados indistintamente e com o mesmo significado.

Quadro 1

Consequências do mobbing na saúde.

\begin{tabular}{lll}
\hline Psicopatológica & Psicossomática & Comportamental \\
\hline Reações de ansiedade & Hipertensão arterial & $\begin{array}{l}\text { Reações de auto e hetero } \\
\text { agressividade }\end{array}$ \\
Apatia & Ataques de asma & Transtornos alimentares \\
Reações de evitação & Palpitações & Aumento de consumo de álcool \\
Problemas de concentração & Doença arterial coronariana & e drogas \\
Humor depressivo & Dermatites & Aumento do tabagismo \\
Reações de medo & Queda de cabelo & Disfunções sexuais \\
Flashbacks & Dores musculares frequentes & Isolamento social \\
Hiper excitação & Perda de equilíbrio & \\
Insegurança & Enxaqueca & \\
Insônia & Dores de estomago & \\
Pensamento intrusivo & Úlceras estomacais & \\
Irritabilidade & Taquicardia & \\
Ausência de iniciativa & & \\
Melancolia & & \\
Mudanças de humor & & \\
Pesadelos recorrentes & & \\
\hline Fonte: Orgaia & & \\
\hline
\end{tabular}

Fonte: Organización Mundial de la Salud (2004) 
inglesa (Inglaterra, Austrália, Nova Zelândia, Estados Unidos, entre outros). No Brasil, frente à gravidade do problema, em 2008 o Ministério da Saúde (Brasil, 2008), com a colaboração de entidades sindicais, lançou uma cartilha denominada "Violência e sofrimento no ambiente de trabalho: assédio moral", com a finalidade de combater toda e qualquer violência no ambiente de trabalho, incluindo o assédio moral.

Os procedimentos que envolvem o assédio moral demonstram ter as mesmas características em qualquer país, além do que, o sofrimento das vítimas e as consequências sobre a sua saúde são descritos exatamente da mesma forma. O que parecem mudar são as características das pessoas atingidas, provavelmente em função do contexto sociocultural. Porém, há diferenças quanto à forma de vivenciar a situação, que favorece a instauração do assédio moral (Hirigoyen, 2002b).

\section{Consequências à saúde e à qualidade de vida}

Quanto mais o mobbing é prolongado, mais graves são as consequências físicas e psicológicas à saúde, por vezes graves e irreversíveis, (Einarsen et al., 2003).

A OMS (2004) refere que o assédio moral pode produzir sérias consequências negativas sobre a saúde do trabalhador, trazendo repercussões nas áreas psicopatológica, psicossomática e do comportamento, com efeitos deletérios também sobre a qualidade de vida.

Não existe forma única para classificar os efeitos do mobbing sobre a saúde. A depressão e os Transtornos Ansiosos são comumente diagnosticados como transtornos, mas outros diagnósticos são estabelecidos com frequência e nomeados de Transtorno de Ajustamento (TA) e Transtorno por Estresse Pós-traumático (TEPT) porque representam tipicamente a resposta aos eventos externos (Quadro 2).

Algumas pessoas, alvos de assédio moral, chegam a cometer suicídio. Os sintomas apresentados são muitas vezes semelhantes aos do Transtorno por Estresse Pós-Traumático no Trabalho (TEPT) (Groeblinghoff \& Becker, 1996; Leymann \& Gustafsson, 1996; Einarsen \& Zapf, 2005). Como o mobbing é caracterizado por uma situação negativa prolongada, o diagnóstico de TEPT é questionado por alguns psiquiatras porque implica na presença de um evento altamente traumático e agudo. Alguns investigadores (Scott \& Stradling, 1994) têm proposto o diagnóstico adicional de Transtorno Prolongado de Coação ao Estresse (TCPE).

Segundo Piñuel y Zabala e Cantero (2003) o mobbing no trabalho é a mais séria ameaça à saúde dos trabalhadores a ser enfrentada neste século. Além das graves sequelas que podem levar a outros problemas relacionados à saúde ocupacional, o mobbing tem afetado significativamente a saúde mental e física da população trabalhadora e a saúde da organização como um todo. Como consequência, a sociedade se converte em vítima, pelo incremento da pressão nos serviços de atenção à saúde e seguridade social. Melhor compreensão teórico-prática se faz necessária para ajudar a estabelecer importantes processos que possam coibir o assédio moral no trabalho e reduzir seu impacto sobre a população trabalhadora.

A seguir, são elencadas as possíveis consequências para a família, o sistema social, o empregador e a sociedade (Hoel. Sparks, Cooper (2001):

- Evasão das reuniões sociais;

- Queixas de mal-estar físico e de enfermidades;

- Abandono aos compromissos sociais;

- Desapego aos vínculos familiares;

- Dificuldades para executar o trabalho;

- Desatenção de seu papel e responsabilidade como pai, mãe, esposo (a), filho (a) etc.;

- Intolerância aos problemas familiares;

- Discussões;

- Perda de relações de amizade;

- Perda de participações em projetos;

- Problemas conjugais e divórcio;

- Custos médicos;

Quadro 2

Características do Transtorno por Ajustamento e do TEPT

\begin{tabular}{ll}
\hline Transtorno de Ajustamento (TA) & Transtorno por Estresse Pós-Traumático (TEPT) \\
\hline O TA é uma condição psiquiátrica que ocorre & O TEPT é uma condição psiquiátrica \\
em resposta a um estressor no qual uma série de & $\begin{array}{l}\text { caracterizada por: (i) reexperiência do evento } \\
\text { com lembranças recorrentes e intrusivas, sonhos } \\
\text { mudanças na vida funcionam como precipitantes. }\end{array}$ \\
$\begin{array}{l}\text { A pessoa apresenta um sofrimento acentuado ou } \\
\text { prejuízo no funcionamento (incapacidade para o } \\
\text { trabalho ou para a realização de outras atividades) }\end{array}$ & $\begin{array}{l}\text { de situações que recordem o evento: (iii) hiper } \\
\text { excitação, que causa dificuldades em adormecer } \\
\text { ou de concentração ou respostas aumentadas de } \\
\text { sobressalto. }\end{array}$ \\
&
\end{tabular}

Fonte: Organización Mundial de la Salud (2004, p.67) 
- Explosões de raiva;

- Violência;

- Piora do desempenho escolar dos filhos.

De forma geral, toda a sociedade se torna vítima porque há aumento da pressão sobre o bem-estar social. As consequências podem variar, de acordo com o sistema de saúde e serviços sociais de cada país. A seguir, são descritos, especificamente, os principais prejuízos para a sociedade:

- Custo de benefícios e proteção social por aposentadoria ou afastamento precoce;

- Altos custos por incapacidade;

- Altos custos por desemprego;

- Perda de recursos humanos;

- Custos médicos e possíveis hospitalizações;

- Perda potencial de trabalhadores produtivos.

\section{Aspectos Preventivos}

\section{Prevenção Primária}

O empregador deve adotar medidas para informar e treinar seus administradores e trabalhadores. Isso pode ocorrer através da produção de códigos de ética e guias de comportamento ético, com informação sobre a natureza e extensão do problema e seus efeitos sobre a saúde e a qualidade de vida; estímulo à confiança no profissionalismo, ao clima de tolerância e liberdade de atitude; negativas à colaboração ou concordância a comportamentos inapropriados. Quanto aos contratos, estes devem incluir termos que regulam a matéria e aplicar sanções para qualquer rompimento das regras.

\section{Prevenção Secundária}

Uma vez que o processo de mobbing começa, pode ser difícil controlá-lo, a não ser que sejam tomadas medidas oportunas e efetivas. Nesse caso um confidente ou um mediador pode ser acionado.

\section{Prevenção Terciária}

Dado que o mobbing pode causar sérias consequências aos trabalhadores, várias medidas podem ser tomadas para ajudar a recuperar a saúde e a dignidade: (i) o diagnóstico precoce dos efeitos sobre a saúde pode ajudar a reduzir as consequências em todos os níveis (individual, familiar e na rede social); (ii) grupos de apoio à sensibilização, que reúna pessoas que tenham sofrido mobbing em diferentes situações. Compartilhar experiências similares permite às vítimas darem-se conta que não são os responsáveis pela ocorrência do fenômeno do mobbing, reconhecer a agressão e, se necessário, modificar seu próprio comportamento.

Em termos absolutos, a prevenção ao mobbing é baseada na possibilidade de se realizar grandes mudanças em relação a valores culturais e individuais, atitudes, expressões verbais e modos de interação. Entretanto, mudança cultural é um processo de longo prazo que pode ser favorecido por uma combinação de esforços para sensibilizar e despertar a percepção ou o insight individual para este fenômeno.

\section{Mobbing: Questões Históricas, Polêmicas E Criticas}

Historicamente, o termo mobbing foi usado para descrever o comportamento predatório de aves e outros animais atacando um indivíduo ou grupo (Davenport et al., 1999).

Em relação aos seres humanos, o termo foi usado pela primeira vez por Lorenz em 1963 em sua descrição do comportamento dirigido a "diferentes", nas escolas e nas forças armadas.

No entanto, o problema foi amplamente elaborado, chamando a atenção pública, por Leymann (1996), a partir de estudos com base nos ambientes de trabalho suecos. O autor descreveu o assédio moral como uma forma de isolamento social, que frequentemente resultava na expulsão do trabalhador-alvo de seu trabalho.

Da análise de 800 (oitocentas) respostas da pesquisa que realizou com trabalhadores, Leymann (1990) identificou uma tipologia de cinco categorias de comportamentos de assédio moral que incluíam (i) agressões que impediam a auto expressão e a comunicação; (ii) ataques ao relacionamento social; (iii) ofensas à reputação; (IV) ofensas com impacto sobre a qualidade de vida geral e profissional e (v) agressões diretas sobre a saúde da pessoa (Leymann, 1996).

Em seguida a Leymann (1996), Schuster (1996) discutiram o assédio moral como forma de exclusão social. A autora argumentou que o fenômeno é um método de exclusão social e identificou o gênero e a classe social como fatores de risco potencial. Além disso, observou que as pesquisas sobre bullying tendiam a focalizar as características de personalidade dos assediadores, enquanto o mobbing, em contraste, era explicado em termos do ambiente de trabalho.

No entanto, a consolidação do tema como objeto de estudo veio a ocorrer com Hirigoyen (2002a), pesquisadora francesa, psiquiatra e psicanalista que tinha grande experiência em terapia familiar, através do lançamento de um best-seller que popularizou o assunto e levou a inúmeros debates. Passou-se, então, a incluir o tema também na área de organização do trabalho, além de sua ocorrência no âmbito familiar.

Parece existir falta de consenso sobre uma definição precisa a respeito do que é o assédio moral no trabalho e discute-se na atualidade a pertinência e validade dos vários instrumentos e métodos utilizados para sua avaliação, incluindo-se os significados dos diferentes termos utilizados para descrever o fenômeno (Cowie, Naylor, Rivers, Smith \& Pereira, 2002).

Para Leymann (1990) o termo mobbing deve ser aplicado a adultos, no contexto ocupacional, sendo 
uma forma de violência psicológica. Já o termo bullying a crianças e adolescentes, no contexto escolar, sendo, preferencialmente, uma forma de violência física.

No entanto, ainda que o conceito de bullying, usado em países de língua inglesa e o termo mobbing, usado em muitos países europeus, possam ter algumas diferenças semânticas e conotações, para todos os fins referem-se ao mesmo fenômeno. Qualquer diferença na utilização desses termos pode estar mais relacionada a diferenças culturais que envolvem o fenômeno, do que a diferenças reais dos conceitos (Einarsen et al. 2003, p. 25). Além disso, qualquer diferença percebida pode ser atribuída a perspectivas pelas quais o fenômeno possa ser visto, ao invés da existência de distinção entre os fenômenos (Zapf \& Einarsen, 2005).

Além da questão da nominação do fenômeno, Anderson (2001) refere ainda que não foi adotada uma definição internacional sobre o mobbing no trabalho. Apesar disso, as definições elaboradas por parte de diversos pesquisadores e instituições internacionais têm circunscrito progressivamente o fenômeno.

Também para a European Agency for Safety and Health at Work, não existe uma definição internacional para o fenômeno e propõe:

Mobbing é um comportamento irracional e repetido dirigido a um empregado ou a um grupo de empregados, que cria riscos para a saúde e a segurança. Nesta definição, "comportamento irracional" refere-se ao comportamento que uma pessoa racional, levando em conta todas as circunstâncias, poderia esperar para vitimizar, humilhar, prejudicar ou ameaçar; "comportamento" inclui ações de indivíduos ou de um grupo para vitimizar, humilhar, prejudicar ou ameaçar; um sistema de trabalho pode ser usado como um meio de vitimizar, humilhar, prejudicar ou ameaçar; "risco à saúde e à segurança" inclui o risco à saúde mental ou física do empregado. $\mathrm{O}$ Mobbing sempre envolve o mau uso ou o abuso de poder, onde os alvos podem ter dificuldades em se defender. (EASHW, 2002, p, 10)

Pesquisas neste campo estão sendo desenvolvidas na Austrália, Nova Zelândia, África do Sul e Brasil, entre outros países. Nesse último, autores ligados à área da Saúde, em particular à área da Saúde Mental, tais como, Barreto (2000; 2003b), Freitas (2001), Heloani (2003a; 2003b, 2004), Guimarães (Guimarães e Vasconcelos, 2008; Guimarães et al., 2005); Guimarães e Rimoli, 2006); Soares e Guimarães (2008) vêm explicitando, por meio de diferentes abordagens, facetas do fenômeno, além de produzirem conhecimento relevante para seu adequado enfrentamento.

No Brasil, segundo Guimarães e Rimoli (2006), os termos mobbing, bullying, assédio moral, assédio psicológico ou terror psicológico no trabalho têm sido utilizados como sinônimos para definir a violência pessoal, moral e psicológica, vertical (ascendente ou descendente) ou horizontal no ambiente de trabalho.

Postula-se nesse artigo a inadequação da nomeação "assédio moral" no ambiente de trabalho, embora se reconheça seu uso consagrado no meio social e nos países hispânicos, recomendando-se a o uso do termo "assédio psicológico" ou mobbing. Essa crítica baseiase na mesma diferenciação apontada na literatura para a uma correta e necessária diferenciação dos termos dano moral $^{2}$ e dano psíquico ${ }^{3}$.

Sob o ponto de vista dos autores dessa obra, quando o assédio no ambiente de trabalho ocorre, dele decorre simultaneamente a existência de sofrimento moral e de sofrimento psicológico. Não se pode dizer que exista sofrimento moral sem sofrimento psíquico. Uma cisão entre essas instâncias (moral e psicológica) que focaliza e remete o fenômeno primariamente à esfera moral, por meio da designação assédio moral, pressupõe que tal instância seria a única ou a primeira a ser afetada. Assim sendo, o "assédio moral" (uma violência especifica da esfera moral do indivíduo) não implicaria, necessariamente, na ocorrência de repercussões psicológicas para o indivíduo, o que não parece correto. Defendem ainda os autores que, se existe sofrimento moral, existe simultaneamente o sofrimento psíquico. Consequentemente, caso exista "assédio moral", a um só tempo existe "assédio psicológico". Cabe, portanto a indagação, do porquê da adoção e manutenção do termo "assédio moral", sendo que no mesmo está implícita e explícita a mencionada cisão e a não adoção do termo "assédio psicológico", que põe em evidência a esfera psicológica, primeira a manifestar as consequências principais do fenômeno sob o ponto de vista da saúde mental?

No ambiente de trabalho, há condutas e procedimentos que podem ser identificados como deletérios, mas que não caracterizam a existência de assédio moral. Certo grau de competição é normal e um componente habitual do dia a dia da vida no trabalho. O mobbing é diferente dos conflitos "normais", sobretudo por duas razões: (i) é caracterizado por ações antiéticas e (ii) é contraproducente para todos (EASHW, 2002, p, 15).

Normalmente, as pessoas ingressam na vida profissional com expectativas específicas (salário, desenvolvimento de competências, progressão

$2 \mathrm{O}$ dano moral é relacionado ao sofrimento da alma e não implica em conformação patológica no individuo, traduzindo simplesmente a idéia de sofrimento por causa de lesões às pessoas ou a seus familiares... O dano moral relacionado ao sofrimento poderá não evoluir para o dano psíquico (Rigolin e Camargo, p,281-300 2004).

$3 \mathrm{O}$ dano psíquico constitui-se ofensa à saúde, em patologia por deterioração, disfunção, e distúrbios nas áreas afetiva e intelectiva, limitando a capacidade de gozo individual, familiar e social. $\mathrm{O}$ dano psíquico poderá ou não ser reparado com tratamento adequado, o que já não corre com o dano moral. (Rigolin e Camargo, p,287-288, 2004) 
de carreira). Seguem também, como objetivos do trabalhador, desenvolver variadas competências profissionais e compartilhar experiências ligadas aos objetivos da empresa. A concorrência é fundamental para alcançar metas, ainda que possam ser incluídos conflitos variados e argumentos que podem até mesmo aquecê-la, mas é baseada em dados factuais, focados no conteúdo, não em valores pessoais. Em uma situação de assédio moral o clima é tenso, a comunicação ambígua e a interação hostil.

Hirigoyen (2002b) também aborda a importância de se limitar o que é ou não assédio moral, e o que são as outras formas de sofrimento no trabalho, apontando para a relevância da distinção entre conflitos e assédio moral nas empresas. Refere que não se deve tratar o assédio moral como se trata o estresse ou como se tratam os conflitos, por exemplo. A autora diferencia assédio, e.g. da pressão no trabalho e enfatiza que, quando não se nomeia um problema, quando não se dá visibilidade ao mesmo ou quando ele é abafado, acaba ressurgindo de forma perversa. Essa gestão perversa está se desenvolvendo cada vez mais, não só nas empresas privadas, como também no setor público (Shallcross, Ramsay e Barker, 2008).

Em uma situação de competição saudável no trabalho, o conflito possivelmente poderá ser resolvido. Esse fato, no entanto, é questionável em uma situação de mobbing. O Quadro 3 abaixo compara conflitos saudáveis e situações de mobbing no ambiente de trabalho.

A literatura sobre comunicação e conflito sempre apontou para a dificuldade de análise das causas dos conflitos (Glasl, 1994; Thomas, 1992). Em primeiro lugar, há o problema de onde parar na cadeia de causas de desenvolvimento do conflito. Em segundo lugar, muitas vezes há mais de um fator que contribui para a escalada de um conflito. Na organização pode haver uma pessoa com tendência para perseguir as outras (isto é, o agressor como causa do assédio moral).

No entanto, para Zapf \& Einarsen (2003) pode ser mais fácil assediar uma pessoa que é de fora do grupo, por causa de sua incapacidade de integração (características da vítima como causa de mobbing). Pode ser ainda mais fácil assediar alguém caso existam condições de trabalho com alto grau de incerteza e sérios problemas organizacionais. Tais condições de trabalho podem levar um indivíduo a cometer vários erros no trabalho, o que, por sua vez, pode ser utilizado como argumento contra o indivíduo (a organização como causa de assédio moral).

A ocorrência de assédio moral pode ser reforçada se houver tensões no grupo de trabalho, para o qual um bode expiatório potencial é um bom "para-raios" (o sistema social como causa de assédio moral). Além disso, pode haver fatores que contribuem para o surgimento de conflitos, e outros fatores que contribuem para a sua escalada.

Zapf (1999) esclarece que a identificação de uma causa de assédio moral, às vezes é uma questão de interpretação, com o que concorda Hirigoyen (2002) ao afirmar que "a noção de assédio moral é, e permanecerá, uma noção subjetiva”.

Se uma deficiência física é tida como motivo para perseguir uma pessoa, pode-se argumentar que a causa do mobbing encontra-se no grupo social, que é incapaz de lidar com as pessoas que são diferentes. Nesse sentido, Hirigoyen (2002b) coloca que é como se, em alguns grupos de trabalho, fosse necessário que todos os indivíduos fossem iguais, que todo mundo produzisse de um jeito definido, que ninguém pudesse ser diferente dos outros, que todos tivessem o mesmo perfil, que todos fossem, de certa forma, como clones, como pessoas com a mesma formatação, com a mesma personalidade. Trabalhadores homogêneos. Uma empresa composta de pessoas clonadas.

Pode haver outros problemas de interpretação também, no caso de uma pessoa com alto desempenho e produtividade (grupo típico de vítimas de assédio moral) que está sob assédio moral (Zapf e Bühler, 1998). Em concordância, Hirigoyen (2002b) coloca

Quadro 3

Diferenças entre situações de conflitos "saudáveis" e de mobbing

\begin{tabular}{ll}
\hline Conflitos "Saudáveis" & Situações de Mobbing \\
\hline Papéis e tarefas claramente definidos & Ambiguidade de papéis \\
Relações de cooperação & Comportamento não cooperativo/boicote \\
Objetivos claros e compartilhados & Imprevisibilidade \\
Relações interpessoais explícitas & Relações interpessoais ambíguas \\
Organização saudável & Falhas organizacionais \\
Choques ocasionais e de confronto & Ações antiética, sistemáticas e de longa duração \\
Estratégias abertas e francas & Estratégicas equivocadas \\
Conflito aberto e discussão & Ações encobertas e negação do conflito \\
Comunicação direta e clara & Comunicação obliqua e evasiva \\
\hline
\end{tabular}

Fonte: Organización Mundial de la Salud (2004) 
que as pessoas mais atingidas pelo assédio moral são precisamente aquelas produtivas demais, motivadas demais, interessadas demais e consideradas como eficientes demais no trabalho.

Em parte, esse problema de interpretação pode ocorrer porque não fica claro se a pessoa com alto desempenho não se conforma com as normas do grupo, comportamento que não é tolerado pelo resto do grupo, ou se o grupo não pode tolerar a pessoa com alto desempenho e que demonstra as suas realizações de forma arrogante e provocadora.

São considerados trabalhadores com risco para a ocorrência do assédio moral, as mulheres, (Salin, 2002; Salin, 2003; Shallcross, Sheehan \& Ramsay, 2008), os imigrantes (Junankar, Paul \& Yasmeen, 2004; Junankar \& Mahuteau, 2005) os trabalhadores de grupo etário acima de 50 anos (Hirigoyen, 2002b), as minorias étnicas (Fox \& Stallworth, 2005; Lewis \& Gunn, 2007; Shallcross, Sheeha, \& Ramsay, 2008), entre outros.

Bennington \& Wein (2000) apontam para o fato de que aqueles trabalhadores que, em geral, são diferentes do grupo dominante, podem ter um risco aumentado de se tornar alvo do assédio moral no ambiente de trabalho

Zapf (1999) refere sobre a existência de múltiplas causas potenciais para o mobbing a serem consideradas: a organização, o assediador, o sistema social das equipes de trabalho e a vítima do mobbing, não devendo ser considerada uma explicação unilateral, em concordância com Guimarães e Rimoli (2006) que consideram o mobbing como uma síndrome psicossocial multidimensional.

Hirigoyen (2002b) pontua como outra dificuldade com relação ao assédio moral a existência de duas dimensões. Há, ao mesmo tempo, uma dimensão coletiva que deve ser tratada pelos sindicatos e tratada de forma coletiva, mas verifica-se, também, uma dimensão de sofrimento individual que precisa de apoio de médicos, psicólogos e outros profissionais afins, para ajudar pessoas a encontrar soluções.

O enfoque do assédio moral como uma perversão do ego, em uma perspectiva fundamentalmente individual, em que ocorre um silencioso assassinato psíquico na esfera estritamente psicopatológica, traduz a posição de vários autores conhecidos, dentre os quais se destaca Hirigoyen (2002a), sobretudo em sua primeira obra, Assédio moral: a violência perversa no cotidiano. Para a autora, o que é necessário saber é que se o assédio moral somente é possível quando a hierarquia ou a direção da empresa permite sua ocorrência e/ou se omitiu.

Se uma empresa é vigilante e severa com relação a essas práticas, o assédio moral não prospera, mesmo quando há um indivíduo particularmente perverso na empresa. Ele será sancionado e não poderá continuar a agir desta forma. Constata-se que cada vez mais empresas e organizações são indiferentes ao bem- estar das pessoas.

Ainda em um contexto teórico, o assédio moral pode ser descrito em termos foucaltianos (Foucault, 1975) como um discurso interrompido porque, embora o fenômeno tenha sido inicialmente relatado no início de 1990 (Leymann, 1990, 1992), esforços continuam sendo feitos para circunscrevê-lo (Zapf \& Einarsen, 2005).

A complexidade do fenômeno do asssédio moral, do mobbing, inicialmente identificado por Leymann (1990), desde então vem sendo validada por outros pesquisadores (Davenport et al., 1999; Moore, 2005; Scutt, 2004; Sheehan, 2004; Westhues, 2002, 2004, 2005, 2006). Esses pesquisadores definem assédio moral como uma agressão psicológica do grupo, que é uma tentativa mal intencionada de forçar determinada pessoa a se demitir do trabalho, por meio de acusações injustificadas, humilhação, assédio emocional e ou terror.

Destacam, ainda, a estrutura e a cultura do ambiente de trabalho, a natureza psicológica dos ataques, na medida em que a organização permite a escalada do conflito para atingir o alvo que é a expulsão.

Hirigoyen (2002b) acrescenta que o assédio moral é um péssimo "negócio" para as empresas, pois não é um método eficiente, na medida em que causa perda de produtividade. Custa caro para as vítimas porque são obrigadas a se tratar, às vezes perdem seus empregos, além do que são, em certos casos, obrigadas a recorrer a um advogado para se defender, portanto. Isto também tem alto preço para a sociedade porque as pessoas ficam doentes e impedidas de trabalhar. Custa caro também para as empresas porque há, efetivamente, o problema do absenteísmo, associado a uma grande desmotivação e perda de produtividade.

A questão do assédio moral precisa ser difundida cada vez mais entre os profissionais de saúde, entre as pessoas que tomam decisões, os políticos, gerentes e administradores, gestores de RH, comunidade, sindicatos e trabalhadores em todo o mundo. É necessário que haja sensibilidade ao sofrimento dos trabalhadores e a este tema, pois somente a tomada de "consciência coletiva e multidisciplinar" em todos os níveis, poderá apontar soluções. A única maneira de combater o assédio psicológico dá-se através da união de esforços de todos esses atores, abordando o problema de diferentes ângulos, com já dito anteriormente, de forma multidisciplinar.

Hirigoyen (2002b, p. 33) acrescenta que a lei é muito importante, primeiro num plano simbólico e também no dissuasivo, para desencorajar este tipo de comportamento, dizendo "Parece-me que em todos os países devemos pensar numa forma de sanção contra o assédio moral, pois ele deve ser identificado e sancionado. Uma lei é muito importante, mas não é suficiente."

Devem existir políticas de prevenção contra este tipo de comportamento. As empresas que não dão 
condições para implantar uma política de prevenção poderão ser mais sancionadas do que aquelas que tentaram restringir o assédio moral ou proibi-lo. Não basta punir o agressor, é necessário mudar as políticas de gestão da empresa e não deixar se instaurar procedimentos de humilhação e desqualificação das pessoas.

\section{Considerações Finais}

O fenômeno, sob o rótulo mobbing, assédio psicológico ou moral, vem sendo bastante estudado em nosso meio na última década, podendo ser considerado um fenômeno mundial, havendo ainda, no entanto, uma escassez de estudos realizados dentro do campo da saúde mental.

Persistem questões polêmicas. Como reflexo desse cenário, a falta de clareza e de consenso na conceituação do mobbing tem provocado confusões e atrasos à sua adequada abordagem e enfrentamento. Apesar disso, as definições elaboradas por parte de diversos pesquisadores e instituições nacionais internacionais têm circunscrito progressivamente o fenômeno. Considera-se de alta prioridade seu reconhecimento, a busca por uma homogeneidade de denominação e da conceituação do problema.

Concorda-se com Hirigoyen (2002b) quando a autora afirma que o enfrentamento do problema e a busca de soluções somente serão possíveis por meio de uma ação de reconhecimento e enfrentamento coletivo, direto e claro e de uma abordagem interdisciplinar, envolvendo médicos do trabalho, psiquiatras, psicólogos, assistentes sociais, sociólogos, sindicalistas, advogados e trabalhadores. Que haja uma tentativa conjunta de se encontrar soluções, dado que se trata de um fenômeno multidimensional.

As práticas do assédio moral continuam a existir nas organizações brasileiras, apesar de sua nomeação e dos consequentes esforços para sua não adoção e expansão, porém, sua denúncia pública tem se intensificado.

\section{Referências}

Anderson, J. (2001). Informe sobre el acoso moral en el lugar de trabajo. Resolución Del Parlamento Europeo sobre el acoso moral en el trabajo. Acta A5-0283 del 16/07/2001. Retirado em 05/02/2010 de http://www.mobbing.nu.

Barreto, M. (2000). Uma jornada de humilhações. (Dissertação de mestrado. Pontifícia Universidade Católica de São Paulo).

Barreto, M. (2003). Violência, saúde e trabalho: uma jornada de humilhações. São Paulo: EDUC.

Bennington, L. \& Wein, R. (2000). Anti-discrimination legislation in Australia: fair, effective, efficient or irrelevant? International Journal of Manpower. 21 (1/2), 21-34.

Brasil. (2008) Ministério da Saúde. Secretaria-Executiva. Subsecretaria de Assuntos Administrativos. Assédio: violência e sofrimento no ambiente de trabalho: assédio moral / Ministério da Saúde, Secretaria-Executiva, Subsecretaria de Assuntos Administrativos. - Brasília: Editora do Ministério da Saúde, 2008. 36 p. - (Série F. Comunicação e Educação em Saúde)
Chappell, D., \& Di Martino, V. (2001). Global Workplace Violence. Geneva: International Labour Office

Chew, I. K. H., \& Horwitz, F. M. (2004) Human resource management strategies in practice: Case-study findings in multinational firms. Asia Pacific Journal of Human resources, 42(1), pp. 32-56.

Cowie, H., Naylor, P., Rivers, I., Smith, P. K., \& Pereira, B. (2002). Measuring workplace bullying. Aggression and Violent Behaviour, 7, 33-51

Davenport, N., Schwartz, R. D. \& Pursell, G. E (1999). Mobbing: Emotional Abuse in the American Workplace, Iowa, USA: Civil Society Publishing

Einarsen, S., Hoel, H., Zapf, D., \& Cooper, C. (2003). The concept of bullying at work: The European tradition. In S. Einarsen, D. Zapf, H. Hoel \& C. Cooper (Eds.), Bullying and emotional abuse in the workplace. International perspectives in research and practice. London: Taylor \& Francis.

Einarsen, S., \& Mikkelsen, E. G. (2003). Individual effects of exposure to bullying at work. In S. Einarsen, H. Hoel, D. Zapf \& C. Cooper (Eds.). Bullying and emotional abuse in the workplace. International perspectives in research and practice. London: Taylor \& Francis.

Einarsen, S., \& Matthiesen, S. B. (2004). Victimisation from bullying at work: We need to understand the process. Occupational Health Psychologist, 1(1), 4.

Fay, D., \& Lührmann, H., (2004). Current themes in organizational change, European Journal of Work and Organizational Psychology, 13(2), pp. 113-120

Flores, M.M.T; Almegua, M L V; Mendoza, R,H, Mobbing: historia, causas, efectos y propuesta de un modelo para las organizaciones mexicanas Rev. Innovar. Vol. 17, no. 29, enero a junio de 2007.

Foucault, M. Vigiar e Punir. Petrópolis: Editora Vozes, 1975.

Fox, S. \& Stallworth, L.E. (2005) Racial/ethnic bullying: exploring links between bullying and racism in the U.S. workplace. Journal of Vocacional Behaviour, 66 (3), 438-456.

Freitas, M. E. (2001). Assédio moral e assédio sexual: faces do poder perverso nas organizações. Revista de Administração de Empresas,. 41 (2), 8-19.

Frenkel, S. J., \& Kim, S. (2004). Corporate codes of labour practice and employment relations in sports shoe contractor factories in South Korea, Asia Pacific Journal of Human Resources, 42(1), pp. 6-31.

Glasl, F. (1994). Konfliktmanagement. Ein Handbuch für Führungskräfte und Berater. (Conflict Management. A Handbook for Managers and Consultants), 4th ed.), Haupt, Bern

Groeblinghoff, D. \& Becker, M. (1996). A case study of mobbing and the clinical treatment of mobbing victims. European Journal of Work and Organizational Psychology, 5 (2), 277-294.

Guimarães, L.A.M.; Vasconcelos, E.F.; Stephannini, I.C. \& Andrade, P.R. (2005) Mobbing em trabalhadores do gasoduto Brasil-Bolívia. Rev Psic Organ e do Trab. (RPOT). Jul dez.Vol. 5, n. 2 ; pp. 15-34

Guimarães, L.A.M; Rimoli, A.O. (2006) Mobbing (Assédio Psicológico) no Trabalho: Uma Síndrome Psicossocial Multidimensional Psicologia: Teoria e Pesquisa, Mai-Ago, Vol. 22 n. 2, pp. 183-192.

Guimarães, L.A.M; Vasconcelos, E.F. (2008). Breves notas sobre Mobbing (assédio psicológico ou moral) no Trabalho. In: Guimarães, LAM; Grubits, S. (org), Série Saúde Mental e trabalho, volume IV. Casa do Psicólogo, São Paulo, pp. 127-136.

Heloani, R. (2003a). Gestão e organização no capitalismo globalizado: história da manipulação psicológica no mundo do trabalho. São Paulo: Atlas.

Heloani, R. (2003b). Violência invisível. RAE - Revista de Administração de Empresas (executivo, volumen 2 número 3, agosto/ outubro.

Heloani, R. (2004). Assédio moral: um ensaio sobre a expropriação da dignidade no trabalho.(versão eletrônica) RAE Revista de Administração de Empresas, janeiro-junho, volume 3, número 1.

Hirigoyen, M.F. (2002a). Assédio moral: a violência perversa 
no cotidiano. Rio de Janeiro: Bertrand Brasil.

Hirigoyen, M.F (2002b) Participação da Dra. Marie-France Hirigoyen- I Seminário Internacional sobre Assédio Moral no Trabalho. Sindicato dos Químicos e Plásticos de São Paulo, Capital (Brasil) no dia 30 de abril de 2002. Retirado em 04/02/2010 de http://www.assediomoral.org/spip.php?article214.

Hoel H, Sparks K. and Cooper C.L. (2001) The cost of violence/stress at work and the benefits of a violence/stress-free working environment, Report commissioned by the International Labour Organization (ILO). Geneva.

Junankar, P.P S. \& Yasmeen, W. (2004). Are Asian Migrants Discriminated Against in the Labour Market?: A Case Study of Australia. IZA Discussion Papers 1167 The Institute for the Study of Labor,Bonn.

Lewis, D \& Gunn, R. (2007) Workplace bullying in the public sector: understanding the racial dimension. Public Administration, 85 (3), 641-665.

Leymann, H. (1990). Mobbing and psychological terror at workplaces. Violence and victims, 5(2), 119-126. 21

Leymann, H. (1992). Adult mobbing in Swedish workplaces. Rikstäckande undersökning med 2438 intervjuer 23.

Leymann, H. (1996). The content and development of mobbing at work. European Journal of Work \& Organizational Psychology, 5(2), 165-184

Leymann, H. \& Gustafsson, A. (1996). Mobbing at work and the development of post traumatic stress disorders. European Journal of Work \& Organizational Psychology, 5(2), 251-275.

Lorenz, Z. K. (1979) A Agressão: uma história natural do mal. Lisboa: Moraes

Mahuteau S. \& Junankar P.N. (2005). Do Migrants get good jobs in Australia? The role of Ethnic networks in job search. IZA Discussion Paper no 3489, Bonn, Germany McKinley, W., Zhao, J., \& Rust, K., (2000), 'A Socio cognitive Interpretation of Organisational Downsizing', Academy of Management Review, 25(1), pp. 227- 243.

Moore, J. (2005). Mobbing is an occupational health and safety issue. Australian Safety Matters Magazine, 40-47

Organización Mundial de la Salud (OMS) (2004). Sensibilización sobre el acoso psicológico en el trabajo. Serie Protección de la salud de los trabajadores. N.04, Geneva.

Parry, K. W., \& Proctor-Thompson, S. B. (2003), 'Leader career development: Who should take responsibility?' Asia Pacific Journal of Human Resources, 41(3), pp. 316- 337.

Piñuel y Zabala, I. \& Cantero, A. O. (2003). La incidencia del mobbing o acoso psicologico en el trabajo en España. Lan Harremanak: Revista de Relaciones Laborales, 7(2), 35-62

Ramsay, S., Barker, M., \& Shallcross, L., (2008) Counterproductive forces at work: Challenges faced by skilled migrant job-seekers. International Journal of Organisational Behaviour, Vol. 13 (2) pp. 110-121.

Rantanen, J. (2000). Impact of Globalisation on Occupational Health. Keynote Address at ICOH 2000, Singapore

Rigolin, A \& Camargo, D.A.(2004) Dano moral e dano psiquico no trabalho. In: Guimarães, L.A.M. \& Grubits, S. (org) Série Saúde Mental e Trabalho, volume IV. Casa do Psicólogo, São Paulo, pp. 281-300.

Salin, D. (2002). Gender differences in prevalence, forms and explanations of workplace bullying. International Conference on Bullying and Harassment at Work. London.

Salin, D. (2003). Bullying and organisational politics in competitive and rapidly changing work environments. International Journal of Management \& Decision Making, 4(1), 35-46.

Schuster, B. (1996). Rejection, exclusion, and harassment at work and in schools: An integration of results from research on mobbing, bullying and peer rejection. European Psychologist, 1(4), 293-317.

Scott, M.J. \& Stradling S.G. (1994) Post-traumatic stress disorder without the trauma. British Journal of Clinical Psychology, $33,71-74$.

Scutt, J. (2004). Mediocrity and the "no change" principle: A recipe for mobbing Paper presented at the Workplace mobbing conference, Brisbane, Australia Shallcross, L., Sheehan, M., \&
Ramsay, S. (2008) Workplace Mobbing: Experiences in the public sector, International Journal of Organisational Behaviour, Vol. 13 (2) pp. 56-70

Shallcross, L., Ramsay, S., \& Barker, M., (2008) Workplace Mobbing: Expulsion, Exclusion, and Transformation, (blind peer reviewed) Australia and New Zealand Academy of Management Conference (ANZAM)

Sheehan, M. (2004) Workplace mobbing: A proactive response. Paper presented at the Workplace Mobbing Conference, Brisbane, Australia

Soares, A. S.; Guimarães (2008) Mobbing: relações com a síndrome de burnout e qualidade de vida em professores universitários de Campo Grande/MS. Artigo em preparação.

Thomas, K.W. (1992) Conflict and negotiation processes in organisations, in Dunnette, M.D. and Hough, L.M. (Eds), Handbook of Industrial and Organisational Psychology, Vol. 3, Consulting Psychologists Press, Palo Alto, CA, pp. 651-718.

Van Dam, K. (2004). Antecedents and consequences of employability orientation. European Journal of Work and Organizational Psychology, 13(1), pp.29-51

Worrall, L., Parkes, C., \& Cooper, C. L. (2004). The impact of organizational change on the perceptions of UK managers. European Journal of Work and Organizational Psychology. 13(2), pp.139-65.

Westhues, K. (2002). At the mercy of the MOB. OH \& $S$ Canada, 18(8), 30-34.

Westhues, K. (2004). Administrative mobbing at the University of Toronto. New York: Edwin Mellen Press.

Westhues, K. (2005). Administrative mobbing of high achieving professors: The envy of excellence New York: Edwin Mellen Press.

Westhues, K. (2006). The remedy and prevention of mobbing in higher education: Two case studies. New York: Edwin Mellen Press.

Zapf. D. (1999) Organisational, work group related and personal causes of mobbing/bullying at work Journal of Manpower. Vol 20 Issue 1-2

Zapf, D., Bühler, K (1998), Exclusion and Stigmatisation at Work, Department of Psychology, J.W. Goethe-University Frankfurt

Zapf, D. \& Einarsen, S. (2003). Individual antecedents of bullying: victims and perpetrators. In S. Einarsen, H. Hoel, D. Zapf \& C. Cooper (Eds.), Bullying and emotional abuse in the workplace: international perspectives in research and practice (pp. 165-184). London: Taylor \& Francis.

Zapf, D. \& Einarsen, S. (2005). Mobbing at work: Escalated conflicts in organizations. In S. Fox \& P. Spector (Eds.). Counterproductive work behaviour: Investigations of actors and targets (pp. 237-270). Washington, DC: American Psychological Association. 